\title{
Instanciando mecanismos de a/r/tografia no processo de criação em arte digital/computacional
}

\author{
Implementación de mecanismos de a/r/tografia en el proceso de creación en arte \\ digital/por computadora
}

Instantiating $\mathrm{a} / \mathrm{r} /$ tographic mechanisms in the creation process in digital and computer arts

\author{
Adérito Fernandes Marcos \\ marcos@uab.pt \\ Universidade Aberta, Lisboa, Portugal
}

\section{RESUMO}

Neste ensaio procuramos trazer para a discussão a forma como mecanismos de $a / r /$ tografia, ou abordagens relacionadas com esta metodologia, podem ser instanciadas no ciclo do processo de criação em arte digital/computacional procurando identificar práticas de experimentação em zonas de fronteira, na reformulação, no repensar, refazer e reconstruir que transforme o processo de criação num processo de investigação, onde a pessoa criativa realça continuamente o sentido e o significado do seu trabalho artístico.

Palavras-chave: arte digital, arte computacional, meditação estética, a/r/tografia

\section{RESUMEN}

En este artículo procuramos traer hasta la discusión como mecanismos de $a / r$ / tografia, o abordajes relacionadas con esta metodología, pueden ser implementados en el proceso de creación en el arte digital o por computadora buscando identificar prácticas de experimentación en territorios de frontera, en la reformulación del repensar, rehacer y reconstruir que pueda transformar el proceso de creación en un proceso de investigación donde la persona creativa realza continuamente el sentido y el significado de su trabajo artístico.

Palabras-clave: arte digital, arte por computadora, meditación estética, a/r/tografia

\section{ABSTRACT}

In this essay we bring into discussion how a/r/tography mechanisms or approach could be instantiated in the creation process cycle in digital art or computer art in order to more effectively identify practices of borderland experiencing, reshaping, rethinking, redoing and remaking that transforms the creation process into a research process, where the creative person enhances continuously the meaning of his/her artwork.

Keywords: digital art, computer art, aesthetic musing, a/r/tography. 


\section{INTRODUÇÃO}

O processo que subjaz ao ato de criação artística ou o processo de criação em si, tem sido objeto de muito debate e pesquisa especialmente durante os últimos 50 anos, mesmo considerando que as questões relacionadas com a arte e a beleza foram tema de análise já na Grécia antiga, por Platão e Aristóteles, por exemplo. Mais recentemente, Duchamp, na sua aula intitulada "The Creative Act" (Duchamp, 1961) afirma que o artista nunca se encontra só com a sua obra; existe sempre um observador/espectador que mais tarde irá reagir criticamente à obra apresentada. Se o artista tiver sucesso na transmissão ao espectador do seu desígnio ou intenção inicial com a sua obra, em termos da mensagem, emoção ou sentimento, reflexão, etc., então uma forma de osmose estética tem lugar através do material inerte (o médium) pois este permite que este fenómeno de comunicação ou mesmo interação aconteçam.

O papel do observador/espectador pode gradualmente assumir uma atitude mais ativa através da interação com a própria obra, dito artefacto, alterando o seu estado ou tornando-se mesmo parte desta (Eco, 1962; Grau, 2003).

De facto o processo de criação em arte digital, considerando aqui as várias categorias de arte computacional ou eletrónica, vulgarmente denominada por arte computacional, baseia-se usualmente na colaboração entre um artista (ou grupo de artistas) e uma equipa multidisciplinar constituída por programadores, técnicos, engenheiros, cientistas e designers, entre outros, que desenvolvem consequentemente trabalho abarcando conhecimento e competências das diversas áreas do saber, partilhando um espaço informacional e comunicacional comum. Este espaço comum integra geralmente acesso a conteúdos informativos digitais, de diversos formatos multimédia, que não raramente são explorados como matéria-prima para a criação de artefactos em arte digital. Os artefactos de webart são bons exemplos deste tipo de obra.

O processo de criação em arte digital baseia-se fortemente no desenho da mensagem do artefacto e o seu desenvolvimento. O meio computacional na forma de ferramentas de edição, comunicação e colaboração em rede assim como os conteúdos informativos digitais atravessa todo o processo de criação. O significado de design, neste contexto, orienta-se para o esforço consciente na criação de um artefacto que seja simultaneamente funcional e esteticamente apelativo. Trata-se de uma perspetiva que herda aspetos tanto do pragmatismo do design em engenharia mas também da inventividade própria e livre da arte aplicada (Laurel, 2003:14; Löwgren e Stolterman, 2007:45). No entanto, contrariamente ao processo puro de design onde a resolução de um problema guia a ação do designer, em arte digital a sistematização não aparece primariamente para esse fim, mas sim para potenciar o propósito da realização, i.e., o artefacto final e todo o processo de reverberação que se faz para atingir esse fim.

Em geral, os artistas adotam um processo similar no desenvolvimento das suas ideias mais criativas, admitindo aqui que nem sempre (em alguns casos raramente) estes têm consciência (ou sequer interesse em tal) do processo embora acabem perpassando as várias fases que o constituem. Inicialmente, a pessoa criativa (artista ou não) tende para a experimentação de forma eventualmente desorganizada ou aleatória, compilando ideias e competências através da leitura ou experimentação. E então, gradualmente um aspeto ou questão (ou grupo de) particular sobressai e ganha a atenção do engenho criador, tornando-se o centro da experimentação e da reflexão, baseando a implementação, onde vários caminhos alternativos de evolução se colocam, que serão eventualmente tentados (no todo ou em parte), no sentido de gradualmente atingir instancias mais refinadas, sendo uma das quais (ou grupo delas) escolhida para suportar a experimentação e o desenvolvimento continuado. Assim, o processo de design abarca várias fases desde a ideia/ conceito inicial (mesmo que o criador não tenha consciência destes) até ao artefacto digital final.

A mensagem que o observador/espectador/utilizador conseguir extrair do artefacto em termos de uma experiência individual ou em grupo proporcionada, que o não deixe indiferente, mas que permita vários tipos de vivências interiores e exteriores, na relação com o artefacto e os outros, constitui a característica central que uma obra em arte digital pode comportar (Marcos e Branco e Carvalho, 2009:16). 
Neste ensaio pretende-se trazer para a discussão a instanciação da metodologia denominada a/r/tografia (Irwin, 2004) no ciclo do processo de criação em arte digital/computacional tendo em vista converter este num processo basilar de investigação que explora intensivamente o realce contínuo que o criador realiza ao sentido e ao significado do seu trabalho artístico.

De facto, uma das atividades centrais do processo de criação em arte digital é a meditação estética, que representa os momentos de contemplação onde o artista revisita a sua visão inicial à luz das decisões tomadas (ou em vias de tomar) durante as fases de desenho e implementação do artefacto e estabelece com este uma relação interior profunda. Esta reflexão estética conduz-se por dois vetores fundamentais, a saber, a apreensão estética relacionada com a necessidade de proporcionar uma experiencia percetiva de prazer, sentido ou satisfação (ou outras); e a inovação tecnológica que abarca as questões da exploração das características de maior potencial da tecnologia, no sentido desta poder efetivamente funcionar como força condutora para a criação de novos discursos estéticos.

O criativo de arte digital imerge num processo de intensa reflexão, enquanto no ciclo de criação, que resulta do amadurecimento gradual da sua visão inicial (theoria), da experimentação prática com as tecnologias e os materiais (praxis) e da construção efetiva ou materialização de protótipos de e do próprio artefacto (poesis), que refina ou abandona (os protótipos), enquanto redefine o seu significado e forma. Existe um processo interior, de questionamento ao nível do "eu", dos vários "eu"s e dos "outros", que assumem a forma dos materiais, das tecnologias, e dos atuais e futuros observadores/utilizadores/experimentadores humanos da sua obra. A prática tem demonstrado que quanto mais detalhado e profundo for o processo de reflexão-experimentação-construção(materialização) levado a cabo pelo criador maior propensão existe para atingir resultados de elevada qualidade estética na perspetiva da experiencia percetiva, cognitiva, emocional, etc. em suma, reflexiva que se oferece.

Este artigo está organizado nos seguintes capítulos: primeiramente descreve-se o processo de criação em arte digital/ computacional como o entendemos e aplicamos, do ponto de vista do desenho da mensagem e a sua implementação tecnológica. No capítulo seguinte é apresentada uma proposta de instanciação da a/r/tografia no processo de criação, transformando este num processo de investigação em arte digital/computacional. Finalmente, no último capítulo, são apresentadas algumas conclusões.

\section{PROCESSO DE CRIAÇÃO EM ARTE DIGITAL/COMPU- TACIONAL}

O processo de criação em arte digital baseia-se comummente no próprio processo de design criativo suportado por várias fases, iniciando no primeiro conceito ou ideia e terminando no artefacto final que se apresenta para exposição.

Como se apresenta na figura 1 o processo de design criativo é iniciado quando o artista/criativo se apodera de um conceito/ideia de partida, mesmo que inconsciente desse facto, e usa-o para lançar-se na criação. Veja-se que a anteceder este momento podem ter ocorrido vários e longos momentos de experimentação livre em busca dessa ideia/conceito seminal.

O processo de design criativo ou da criação em arte digital/computacional não é todo linear, i.e., os artistas podem avançar e recuar na sequência de atividades, saltar alguma delas ou focar-se mais numa em particular. Trata-se de um processo que é usualmente muito dinâmico, embora a visão do artista esteja sempre presente (Marcos et al, 2009:1516) (Marcos e Zagalo, 2011:145).

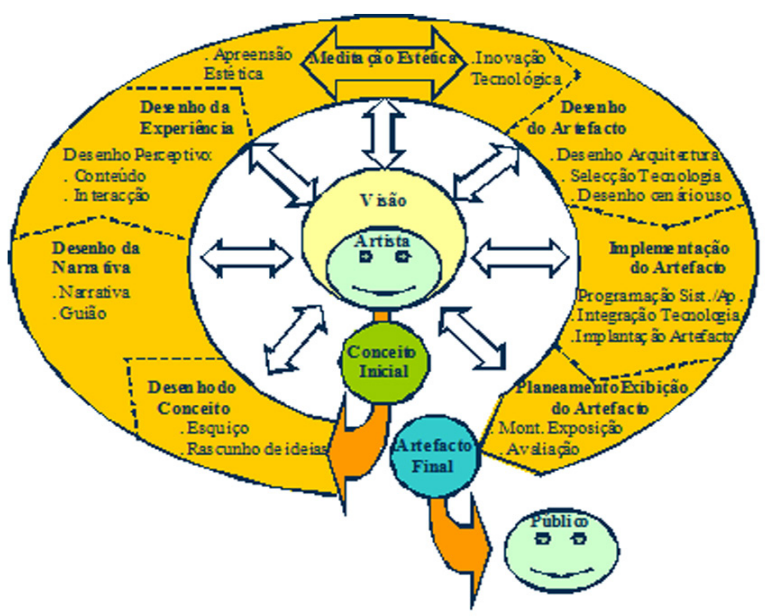

Fig. 1. Vista geral das diferentes fases do processo de criação (ou design criativo) em arte digital/computacional. 
Existem várias fases do processo de criação, cada uma cobrindo uma contribuição importante na formação do artefacto final. Estas fases são descritas de seguida:

Fase de Desenho da Mensagem:

- Desenho do Conceito: nesta atividade o artista envolve-se no ato de converter a sua ideia/conceito ou visão num conjunto de esquiços, desenhos informais, i.e., a abstração concretiza-se numa estrutura tangível em perspetiva. $O$ artista realiza esquiços, num ato de exploração, onde não se pretende qualquer trabalho final. Os resultados desta atividade são constituídos por esquiços, desenhos vários, com maior ou menor organização, que permitem ao artista visionar diferentes concretizações possíveis para a sua ideia/ conceito de partida, no sentido de estabelecer uma primeira tentativa de uma composição final mais complexa.

- Desenho da Narrativa: aqui o artista, tomando os resultados da atividade anterior, concebe uma composição, uma construção feita de uma sequência de eventos que permita arquitetar a mensagem através do envolvimento do espectador/utilizador numa narrativa suportada pelo próprio artefacto. Esta narrativa da mensagem, que subjaz ao conceito inicial, é desenhada tendo em consideração aspetos tais como a estrutura do conceito e a sua concretização no futuro artefacto, as suas partes constituintes, suas funções e relações inter-intra-artefacto. A narrativa assume a forma de uma sequência cronológica de temas, motivos, e linhas de enredo. $O$ resultado desta atividade pode ser resumido como sendo o desenho de uma mensagem como uma história que melhor possa envolver o espectador/utilizador no artefacto.

- Desenho da Experiência: esta atividade abarca um contributo para o processo de desenho da mensagem tendo em consideração o seu conceito seminal e a narrativa, no sentido de conceber características específicas a imprimir a cada evento da narrativa para que este possa proporcionar ao espectador/utilizador a experiência humana (nas suas várias dimensões) pretendida. A conceção ou planeamento desta experiencia humana em cada evento da narrativa é realizada levando em linha de conta preceitos individuais ou de grupo, conhecidos ou suspeitados, ao nível das crenças, emoções, conhecimento, habilidades, experiências e perceções. $O$ desenho da experiência deverá assim ter em conta aspetos importantes da natureza humana ao nível dos estímulos e da atenção, bebendo de conhecimentos e competências de áreas como a psicologia percetiva, ciência da cognição, desenho ambiental, háptica (ciência e tecnologia do sentido do tacto), desenho de conteúdos informativos, desenho de interação, computação heurística, e pensamento do design, entre outros.

Meditação Estética: esta atividade é central no processo de criação, pois representa os momentos de contemplação onde o artista/criativo revê, revisita a sua visão seminal à luz das decisões tomadas (ou apenas planeadas) (ver fig. 1) durante o desenho e desenvolvimento do artefacto. Identificam-se dois vetores condutores nestas atividades, a saber:

- Apreensão Estética: trata-se do processo de refletir e conceber a integração de características no artefacto que eventualmente proporcionem uma experiencia de prazer, significação e satisfação, provenientes especificamente de manifestações e estímulos sensoriais gerados a partir do artefacto por via da sua forma, cor, imersão sensorial, som, textura, design ou ritmo, entre outros. A dimensão estética aqui relaciona-se exclusivamente com a natureza percetiva dos vários componentes do artefacto.

- Inovação Tecnológica: processo de reflexão para conceber a integração de aspetos inovadores na (re)modelação, utilização, combinação e exploração da tecnologia digital que forma e concretiza o artefacto. Isto aponta para a dimensão da criação estética dos meios computacionais, i.e., a tecnologia como uma força condutora na criação de novos discursos estéticos. Dado o facto da tecnologia digital se encontrar em rápido desenvolvimento torna-se desejável procurar retirar todo potencial que a tecnologia possa oferecer através da integração de funcionalidades no limite do exequível. 


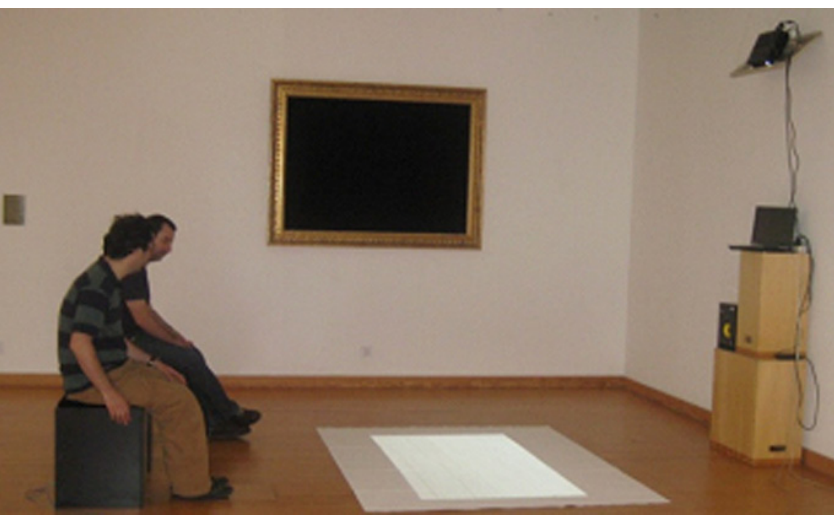

Fig. 2. Artistas digitais durante o desenvolvimento do artefacto, experimentando com um protótipo (artefacto: “Gato, o novo flâneur" por Ra quel Pinto \& Filipe Leite). (Cortesia do Mestrado em Tecnologia e Arte Digital da Universidade do Minho)

Fase de Desenvolvimento do Artefacto (ver fig. 2):

- Desenho do Artefacto: esta atividade diz respeito ao desenho do sistema ou aplicação computacional, abarcando todos os seus componentes de qualquer índole (mecânico, eletrónico, materiais, etc.), que irão concretizar o artefacto final. Inclui o desenho da Arquitectura', da interface e da interação do sistema, assim como a seleção de tecnologia para a sua implementação. Visto que o artefacto final comporta, geralmente, alguma forma de interação com o público, seja com o espectador/utilizador individual ou em grupo, esta atividade acaba também por incluir um cenário de uso, i.e., o espaço e a forma como o artefacto será "usado". O desenho aqui adota uma dimensão híbri$\mathrm{da}$, tanto explorando considerandos funcionais próprios da engenharia (design rigoroso baseado na exploração da tecnologia) como aqueles mais de índole estético e orientados à concretização de conceitos ou ideias, sem preocupação funcional mas sim estéticos, próprios da arte aplicada.

- Implementação do Artefacto: nesta atividade o artista/criativo procede com a implementação concreta do próprio artefacto. Esta atividade incorpora tarefas tais como a programação de sistemas e aplicações, teste e debug, assim como, integração de tecnologia e a implantação final do artefacto como obra terminada. Tal exige do artista, geralmente, que seja detentor de competências técnicas e de programação (que permite alterar o cerne do artefacto) se este desejar ter um controlo mais direto sobre o processo de implementação do seu artefacto. O artista poderá even- tualmente ser assistido por uma equipa de programadores e tecnólogos; no entanto, para se manter ao comando do trabalho de criação artística, precisamente nesta fase, o artista terá de possuir sempre um certo domínio das tecnologias.

- Planeamento da Exposição do Artefacto: nesta atividade junta-se e procura-se responder a todas as questões relacionadas com o planeamento e a montagem da exibição do artefacto. Estamos no estágio final da concretização da obra, onde o artefacto é apresentado ao mundo, i.e., a obra encontra o seu público. O sucesso deste encontro depende incrementalmente da atratividade do próprio artefacto; da forma como o espaço de exposição está organizado; como a logística das diferentes componentes do artefacto é gerida e mantida; e ainda a contextualização / integração do artefacto no todo da exposição (sendo conjunta). Veja-se que esta atividade beberá diretamente das decisões tomadas antes na fase de desenho da mensagem e implementação do artefacto, e ainda, especialmente tendo em conta a configuração planeada para o cenário de uso. Os artefactos podem ser apresentados em museus, galerias e feiras de arte, associações artísticas, espaços comerciais e publicitários, espaços educativos e lúdicos, etc. ou ainda em algum espaço virtual na Internet.

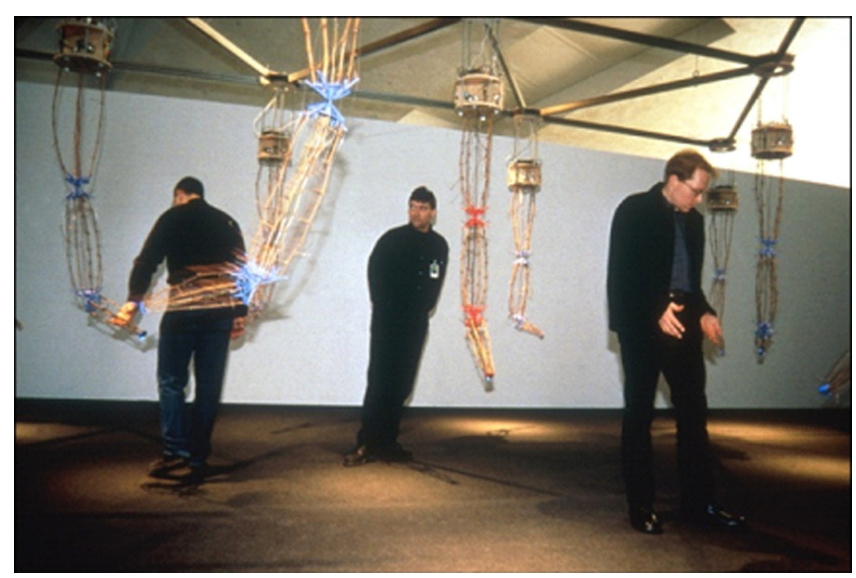

Fig. 3. Artefacto: "Autopoeisis" por Ken Rinaldo (2000). O artefacto envolve o utilizador, detetando a sua presença e procurando abraça-lo.

O processo de criação em arte digital/computacional tem a propensão para levar o artista a imergir em momentos de intensa reflexão representados em grande medida, pela fase da Meditação Estética, e ainda por ciclos em que se retorna à sua visão primordial, amadurecendo-a e reintegran- 
do-a na atividade de criação onde se encontra assumindo práticas semelhantes à metodologia de investigação denominada a/r/tografia (Irwin, 2004).

No próximo capítulo apresentamos uma proposta de instanciação da $a / r /$ tografia no processo de criação em arte digital/computacional, analisando como tal permite transformar este num processo de investigação em arte digital/ computacional.
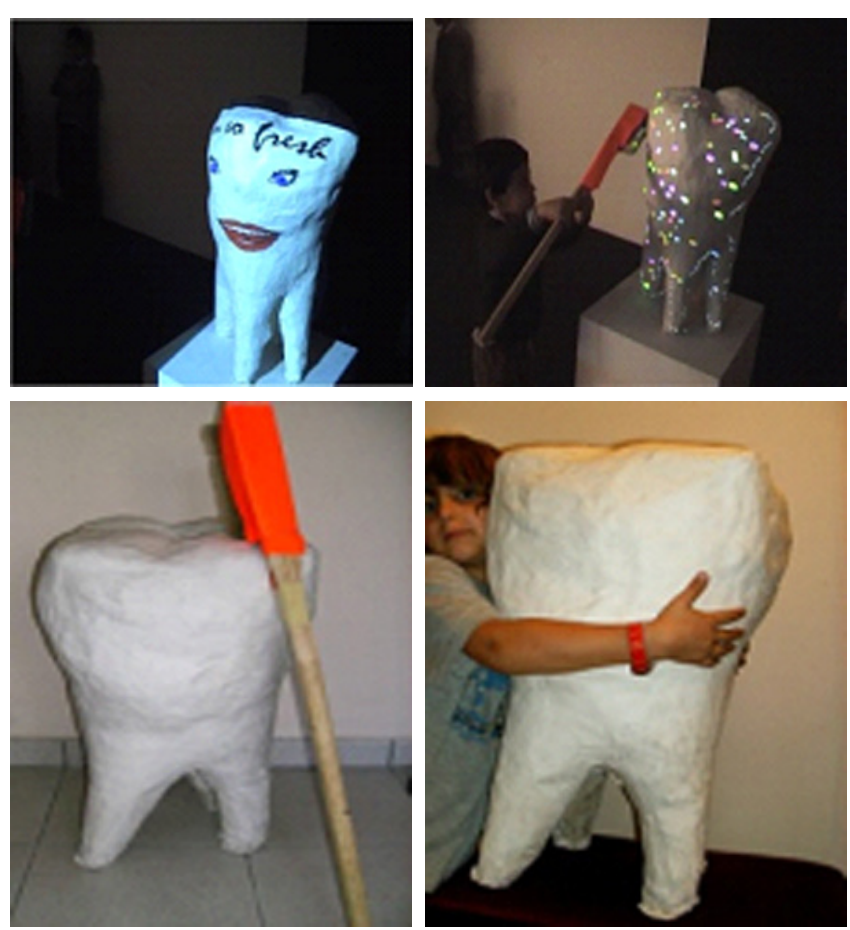

Fig. 4. Utilizadores (crianças) interagindo com um artefacto (artefacto: "Virtually Brushing my Tooth" por Cristina Sylla \& Heduino Rodrigues, 2008). (Cortesia do Mestrado em Tecnologia e Arte Digital da Universidade do Minho)

\section{INSTANCIANDO A/R/TOGRAFIA NO CICLO DE CRIAÇÃO EM ARTE DIGITAL/COMPUTACIONAL}

O processo de criação em arte digital/computacional é atravessado horizontalmente por ciclos mais ou menos longos de profunda reflexão sobre o processo em si e a criação em curso, onde o artista se questiona continuamente (sentido para o interior - "eu") sobre a sua visão primordial e os conceitos/ideias iniciais à luz do "outro" (sentido para o exterior - "outro") seja este o processo de criação, os materiais, as tecnologias e ferramentas, os artefactos em protótipo, etc.
Existe um contínuo repassar pelas três formas de pensamento/conhecimento artístico/filosófico, a saber:

- a visão primordial do artista (theoria) que evolui ao longo do processo de criação, que sustenta a obra desde o seu primeiro ato de criação;

- a experimentação prática com as tecnologias (incluindo sistemas, ferramentas e conteúdos informativos digitais) e os materiais (praxis), que comporta avanços e recuos (ou mesmo desaires), que continuamente reforçam uma proximidade, na forma de uma relação que o artista estabelece com estes (a matéria prima e as ferramentas de criação), aprendendo a conhecer a sua personalidade em termos das suas características, potencialidades e limitações;

- a construção/materialização efetiva do artefacto (poesis), onde vários protótipos podem ser concretizados, que se refinam e adotam ou abandonam, enquanto se vai redefinindo o seu significado e forma.

$\mathrm{O}$ artista adota portanto uma postura de questionamento e reflexão, numa busca constante entre estas três formas de pensamento, perscrutando o espaço entre elas, sem atribuir preponderância a uma em detrimento da outra. Daqui se pode construir um equilíbrio que será tanto melhor conseguido quanto melhor for verificável ao nível da qualidade estética da obra produzida, i.e., o artefacto final.

No processo de criação em arte digital existem dois ciclos principais ou momentos que delineiam a cogitação contínua levada a cabo pelo artista: a atividade de meditação estética; e os momentos em que o artista revisita a sua visão seminal confrontando-a com o processo de criação, no estado em que se encontra, com os materiais e as ferramentas, e até, se já em fase implementação e teste do protótipo do artefacto, com espectadores/utilizadores e o próprio protótipo.

A meditação estética no processo de criação em arte digital/ computacional implica uma postura de contemplação ou reverberação sobre os motivos / motivações mais profundas e íntimas para o sentido/significação do artefacto almejado, numa perspetiva geralmente de intervenção na história e sociedade. 
Redefinições da visão primordial são geradas continuamente podendo moldar e re-moldar de novo a evolução e desenvolvimento do artefacto emergente, dando-Ihe um sentido de (in)coerência e sentido à sua mensagem / narrativa subjacentes.

Meditação estética significa aqui também a conceção e criação de mecanismos de questionamento do mundo através de um processo de interação com o artefacto em desenvolvimento para (re)criar significados ou reforçar sentidos.

Por outro lado, meditação estética abarca a intensa pesquisa pela inovação tecnológica onde o artista se envolve num processo de integração de inovação visando remoldar, utilizar, combinar e explorar tecnologia digital na senda de novos discursos estéticos, vetores de exploração que possam abrir portas para novas perceções, em última instancia, novas experiencias artísticas (Marcos e Zagalo, 2011).

Para Kant (1961) a contemplação da beleza consistia num julgamento que necessitava de afetar o espectador duma perspetiva sensorial, emocional e intelectual, conjuntamente. Meditação estética implica sobretudo dar ênfase à experiencia sensível que o artefacto proporcionará ao utilizador, seja esta de índole percetiva, emocional, cognitiva, lúdica, educativa, de novos sentidos e significados, etc. em suma, que leve o espectador ao questionamento e à reverberação sobre aspetos do seu imaginário interior, da sociedade e da vida, tão comuns às obras contemporâneas, visando, enfim, uma forma de osmose estética.

Consideramos que o processo de criação em arte digital/ computacional transforma-se num processo experimentação estética, quando imprime fortemente práticas de contemplação que perpassa entre as três formas basilares de pensamento e conhecimento artístico - conhecimento (theoria), prática (praxis) e materialização (poesis) - através da meditação estética e a revisita contínua da visão primordial do artista. Os artistas digitais à semelhança dos $\mathrm{a} / \mathrm{r} /$ tógrafos vivem as suas práticas, representam as suas significações e questionam as suas posições e ideias e conceitos à medida que integram conhecimento, prática e materialização através de experiências estéticas que proporcionam sobretudo sentidos e significações em detrimento de factos (Irwin e Springgay e Kind, 20078:xx).
O processo de criação em arte digital/computacional transforma-se num processo de investigação em arte e tecnologia quando propicia a criação de novos discursos estéticos, novas experiencias artísticas, novas aplicações e significações da tecnologia, em suma, permite ampliar significações e sentidos que se revelam através de sucessivas interpretações das relações complexas que são continuamente criadas, recriadas e transformadas.

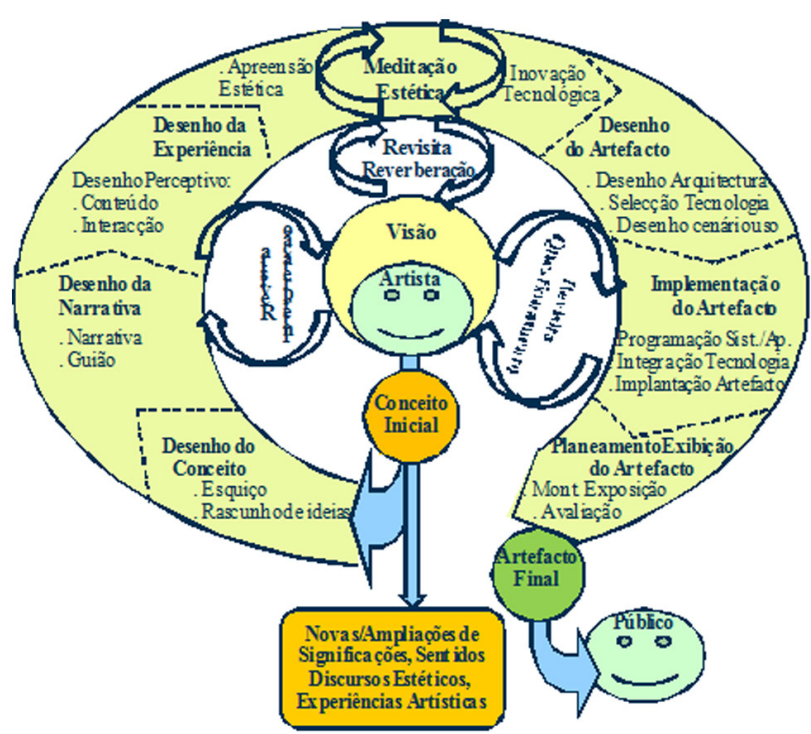

Fig. 5. A a/r/tografia no processo de criação em arte digital/computacional.

O processo de criação em arte digital/computacional permite aceder ao espaço entre a teoria (visão primordial) e a métissage feita de prática e materialização abrindo o espaço entre o artista, investigador e também professor. 0 artista digital embrenha-se e vive numa zona de contínua fronteira, sempre em mudança, acompanhando a rápida evolução das tecnologias digitais, questionando, interpretando, e gerando novas significações.

Na fig. 5 propomos uma instanciação da a/r/tografia no processo de criação em arte digital/computacional. O processo mantém-se, em grande medida inalterado, onde se reforça, isso sim, os dois ciclos de reverberação: a meditação estética; e a revisita contínua da visão primordial.

\section{CONCLUSÕES}

Neste artigo na forma de ensaio analisamos o processo de criação em arte digital/computacional descrevendo as suas 
diferentes fases e atividades. Constatamos que enquanto imersos no processo de criação os artistas digitais usualmente envolvem-se num modo de reflexão tanto orientado para o seu interior como exterior repensando conceitos, ideias que subjazem o artefacto ou instalação que se encontra em configuração, e consequentemente, redefinem o seu significado e forma. Existe um processo do "eu" e do "outro" semelhante ao que encontramos na metodologia da a/r/tografia.

Foi proposta uma instanciação da a/r/tografia ao processo de criação em arte digital/computacional que em grande medida deixa este inalterado apenas se reforça todo o processo de reflexão/meditação tanto ao nível da meditação estética como na revisita da visão primordial do artista face à metissage feita do processo, materiais, tecnologias e eventuais utilizadores. O processo de criação em arte digital assume assim a forma de experimentação artística e investigação em arte pois permite ampliar significações e sentidos que se revelam através de sucessivas interpretações das relações complexas que são continuamente criadas, recriadas e transformadas e que constituem o caminho para e a própria obra que se materializa como artefacto de arte digital/ computacional.

\section{REFERÊNCIAS}

DUCHAMP, M. (1961).The Creative Act. Lecture at the Museum of Modern Art. New York. Published in Art and Artists, 1 (4).

ECO, H. (1962). The Open Work. Harvard University Press.

ELIOT T.S. (1920). Tradition and Individual Talent in The sacred wood; essays on poetry and criticism. London: Methune.

GRAU, O.(2003). Virtual Art - From Illusion to Immersion. Cambridge, Massachusetts: The MIT Press.

GREENE, R. (2005). Internet Art. London: Thames \& Hudson Ltd.

LAUREL, B. (2003). Design Research: Methods and Perspectives. Cambridge, Massachusetts: The MIT Press.

LÖWGREN, J. \& STOLTERMAN, E. (2007). Thoughtful interaction design - a design perspective on information technology. Cambridge, Massachusetts: The MIT Press.

IRWIN, R. (2004). A/r/tography as metonymic, metonymic, metissage. In A/r/tography: Rendering self through arts based living inquiry. ed. R.. L. Irwin \& A. Cosson (Eds.), 27-38. Vancouver, BC: Pacific Educational Press.
SPRINGGAY, S. \& IRWIN, R. \& Kind, S. (2007). A/R/Tographers and living inquiry. In Handbooks of the arts in qualitative research, ed. J. G. Knowles \& A. L. Cole (Eds.), 83-92. Toronto, ON: SAGE.

MARCOS, A. (2007), Digital Art: When artistic and cultural muse and computer technology merge. IEEE Computer Graphics and Applications, 5(27), 98-103.

MARCOS, A. \& BRANCO, P. \& Carvalho, J. (2009). The computer medium in digital art's creative development process. In J. Braman \& G. Vincenti \& G. Trajkovski (Eds.), Handbook of Research on Computational Arts and Creative Informatics (1-15). Hershey, Pennsylvania:IGI Publishing.

MARCOS, A. \& ZAGALO, N. (2011). Instantiating the creation process in digital art for serious games design. Entertainment Computing - Serious Games Development and Applications, 2(2), 143-148.

KANT, I. (1961). Observations on the Feeling of the Beautiful and Sublime. Trans. J. T. Goldthwait. Berkeley, CA: University of California Press. 